\title{
La acomodación en los sermones de Luis de Valdivia (1621)
}

\author{
The “accommodation” in the sermons by Luis de Valdivia (1621)
}

\author{
Nataly Cancino Cabello \\ Universidad de Sevilla, C/ Palos de la Frontera, s/n, Sevilla-41004, España. Correo electrónico: nataly. \\ cancino@hotmail.com
}

Con el fin de facilitar la evangelización de los mapuches, Luis de Valdivia imprime, en 1621, en Valladolid, Sermón en lengua de Chile, obra "acomodada a la capacidad" de los indígenas. Dicha acomodación corresponde a un proceso de diferenciación del receptor en el cual este se construye como un otro determinado por su cultura tanto en el ámbito de sus creencias como en su capacidad cognitiva para la comprensión del discurso. Esto queda de manifiesto con las estrategias que el hablante despliega y que revisamos en este trabajo.

Palabras clave: mapuche, sermones, Luis de Valdivia, acomodación del discurso.

In order to facilitate the Mapuche people evangelization, Luis de Valdivia printed in 1621, in Valladolid, Sermón en lengua de Chile, a work "adapted to the capacity" of the indigenous. This "accommodation" corresponds to a differentiation process in which the listeners are constructed as others determined by their culture both in the scope of their beliefs as in their cognitive capacity for the discourse comprehension. This is demonstrated through the strategies deployed by the speaker and are reviewed in this paper.

Key words: Mapuche people, sermons, Luis de Valdivia, accommodation of the speech.

\section{Presentación}

Esta investigación toma como objeto de estudio la obra bilingüe mapudungunespañol Sermón en lengua de Chile del jesuita granadino Luis de Valdivia, impresa en Valladolid, en 1621, con el fin de facilitar la evangelización mapuche, pueblo indígena en conflicto bélico con las tropas españolas. El sermonario se inserta en la línea de institucionalización práctica de la guerra defensiva que el mismo autor había desarrollado y defendido durante las décadas anteriores. En ese sentido, es una consecuencia de las indicaciones establecidas por el III Concilio de Lima (15821583), de acuerdo con las cuales la cristianización en la Archidiócesis (de la que dependía Chile) debía realizarse en las lenguas vernáculas y los textos utilizados en la catequesis y la administración de sacramentos debían ser una traducción de los complementos pastorales dirigidos a los indígenas del área andina, cuya elaboración 
se ordena en español, quechua y aimara. Aunque no se explicita, Sermón en lengua de Chile se vincula de manera directa con el Tercero catecismo de dichos complementos, el que le sirve como modelo inmediato (Cancino Cabello 2012). Corresponde, por tanto, a una adecuación a las características culturales del pueblo mapuche en la búsqueda de asegurar la comprensión del discurso y el cumplimiento de los fines argumentativos del mismo (Cfr. Cancino Cabello 2011a).

Dicha acomodación obedece a la preceptiva de la predicación, según la cual, en la elaboración del tipo textual sermón, se debe considerar el público al que se presenta, en concordancia con la tradición europea de oratoria sagrada que se trasladó a América. Esta se remonta al uso que San Agustín (1969 [396-397/426-427] y 1998 [400]) hace de la retórica clásica (Cfr. Urrejola 2011) para establecer un modelo que se institucionaliza en el seno de la Iglesia católica (Murphy 1989), con la creación de una doctrina cristiana ligada a la oratoria y a la elocuencia (Briscoe 1992).

En el sermonario, la acomodación se convierte en una auténtica traducción a la cultura del otro, aunque se realizó desde la posición eurocentrista del evangelizador, quien vio, pero nunca entendió esa otredad como una forma válida y suficiente, por sí misma, para enfrentarse a la vida y como mecanismo de desarrollo. Este proceso no se muestra solamente en el plano de la comprensión de la cultura, sino también en la interpretación de esta como un "universo mental" que implicaba un "pensar" diferente, en una relación en la que el ser indígena ocupa el punto más bajo de la escala en referencia al colonizador. Esta construcción simbólica se produce porque la teología pastoral en América dio "fundamento a la superioridad y al ejercicio del poder de los españoles sobre los indios, construyendo discursivamente la representación de la diferencia cultural como supremacía de la cultura europea" (Aedo Fuentes 2005: 103).

Nuestro propósito es dar cuenta de esa doble “acomodación” discursiva al mundo cultural y a la capacidad cognitiva mapuche. Realizamos este ejercicio en consideración de la importancia del contexto, entendido como el mundo mental compartido entre los interlocutores (van Dijk 2009 y 2012). Nos servimos de esta noción porque resulta operativamente válida si consideramos que la historia externa de los constructos lingüísticos es necesaria para su comprensión en cuanto unidad de comunicación, por lo que los aspectos interdisciplinarios son fundamentales para la interpretación de los mismos, más cuando se trata de escritos interculturales no contemporáneos como ocurre con muchos de los textos de la Conquista y la Colonia americanas (Cancino Cabello 2011b). Nuestro interés por esta producción surge en un momento en el que cada vez son más numerosos los estudios lingüísticos sobre estos escritos, labor que se enmarca en la posibilidad de acceder a "un pasado rico en tradiciones, formas de apreciar la sociedad y la relación con el entorno", según indica Contreras Seitz (2013: 76) como objetivo para el CorDECh ${ }^{1}$. De este modo, la labor del lingüista supera la posición inmanentista que considera al lenguaje como un fin en sí mismo (Cfr. Bustos Tovar 2000) y se pone al servicio de la comprensión de las dimensiones culturales en que este ha operado.

\section{ANTECEDENTES DE LA OBRA: HISTORIA EXTERNA}

Desde los primeros encuentros con los conquistadores españoles, el pueblo mapuche dio muestras de una belicosidad que llevó al fracaso de las huestes

Corpus diacrónico del español de Chile. 
extranjeras, de modo que la Corona hispana debió acudir a otras formas de conquista. En ese contexto, después de los acontecimientos del llamado "desastre de Curalaba" (1598-1602) -cuando los indígenas arrasaron con los dominios españoles del sur de Chile (Ramón 1961)-, Luis de Valdivia propuso la estrategia de la guerra defensiva, que consistía en una conquista espiritual ${ }^{2}$, en la cual, a través de un sistema de parlamentos, se persuadiría a los mapuches para abandonar sus costumbres y convertirse al cristianismo, mientras que las ofensivas bélicas se ejecutarían solo en caso de que los indígenas atacaran primero ${ }^{3}$.

Este misionero granadino había llegado unos años antes al Reino, junto con los primeros jesuitas que se asentaron en Santiago, en 1593. A su arribo, los religiosos debieron repartirse las tareas para facilitar la atención espiritual de los diversos grupos con que se encontraron y Luis de Valdivia se hizo cargo de la evangelización de los indígenas (Foerster 1996). De este modo aprendió su lengua, por lo que produjo un tratado metalingüístico sobre el mapudungun ${ }^{4}$.

También conoció las condiciones en las que vivían los mapuches, tanto por su contacto con ellos en Santiago como por su participación en las misiones volantes en los fuertes del sur (Foerster 1994). El sacerdote fue consciente de la inviabilidad de la guerra que se llevaba a cabo en contra de estos indígenas, ya que representaba un alto coste económico y humano para la Corona, inversión que no se recompensaba, pues el fracaso militar era evidente (Díaz Blanco 2010). Por otra parte, señaló que este tipo de dominio convertía al mapuche en un ser esclavizado (sus principales objeciones fueron en contra del servicio), que desconfiaba del español y de la fe católica que se pretendía implantar (Valdivia 2011 [1604]).

Su propuesta recibió tanto la oposición de los encomenderos (Mires 2006), como de los políticos (Amunátegui Solar 1934). El jesuita también despertó recelos en el interior de su Orden y, finalmente, en 1621 fue enviado a Valladolid, donde murió en 1642 (Díaz Blanco 2010).

Pocos meses después de su llegada entrega a la imprenta Sermon en lengva de Chile, de los mysterios de nvestra santa fe catholica, para dedicarla a los indios infieles del reyno de Chile, dividido en nveve partes pequeñas, acomodadas a fu capacidad, probablemente escrita o preparada con antelación. Creemos que esta obra fue impresa con premura, pues anuncia sermones posteriores de los que no se han tenido noticias y porque sus elementos paratextuales son rudimentarios. Por ello, nos explicamos la impresión como un último intento del jesuita por mantener los lazos con Chile y su injerencia sobre la guerra defensiva.

\section{ACOMODACIÓN DEL DISCURSO DE ACUERDO CON PARÁMETROS CULTURALES}

Cuando el locutor acomoda la obra a las características de la cultura mapuche, toma de la doctrina cristiana los contenidos que cree pertinentes para la realidad

\footnotetext{
Concepto con que Ricard (1964) se refiere al caso de Nueva España.

Sobre este tema puede consultarse Díaz Blanco (2010).

4 Se trata de Arte y gramática general de la lengua que corre en todo el Reino de Chile (Lima, 1606). Valdivia también trabajó sobre el millcayac y el allentiac, lenguas habladas por los indígenas trasladados desde Cuyo, actual Argentina. Comúnmente se les conoce como "idiomas huarpes" y de las designaciones de "allentiac" y "millcayac" solo se tiene noticias por los trabajos de Valdivia (Medina 1918).
} 
del pueblo al que se enfrenta. En ese sentido, concibe y construye un alocutario 5 determinado por su cultura y representante de la otredad en el ámbito de las conductas. No obstante, en este esfuerzo apreciamos que el jesuita no logró comprender las manifestaciones culturales indígenas, sino que se las explicó en la medida en que sus propias creencias se lo permitieron o bien las manipuló de modo que las hizo explicables dentro de sus parámetros ideológicos.

En ambos casos, la inclusión de una interpretación de la cultura mapuche, que no representa necesariamente aquella conocida por el alocutario, es un elemento retórico que vuelve falible la argumentación. En los sermones, lo anterior se manifiesta con varios recursos: el uso de prácticas y costumbres mapuches como argumentos, la creencia en un topos compartido y la consideración de la cultura mapuche como autoridad.

\subsection{Argumentos por referencia al mundo mapuche}

Estos argumentos enfatizan los contenidos como medios de prueba y se usan porque el hablante necesita el conocimiento del otro para convencerlo. Utiliza, por lo tanto, sus creencias y tradiciones porque tienen la ventaja de ser conocidas por el oyente, se ubican en el plano de lo empírico - puesto que han sido practicadas con un alto nivel de conciencia ceremonial-y tienen un valor de concreción del que carece el ideario cristiano que se da a conocer.

Este tipo de argumento manifiesta la dinámica intercultural entre dos espacios cognitivos diferentes (el de los misioneros y el de los mapuches) que se han encontrado en un proceso de dominación de uno sobre otro y que pretende la aculturación de los indígenas, ya que busca, en definitiva, que dejen de ser lo que son. Esta dinámica se instala en los sermones por su función polémica (Cfr. Kosel 1997), que juzgamos como parte de la preceptiva general de la evangelización en zonas de contacto.

Para el emisor, la diferencia entre las creencias de las culturas se centra en la dicotomía acierto/error, en la que los polos se excluyen mutuamente y no hay escalaridad en la relación: el acierto está representado por el cristianismo, mientras que el mundo mapuche es el opuesto negativo. Esta incorporación le otorga un grado de autoridad y reconocimiento a la cultura indígena, pero se utiliza para que el locutor, situado en un grado superior de la escala de valores, le reste consideración, catalogando las prácticas culturales indígenas como erradas, a las cuales opone la tesis defendida por él. Con ello, se disminuye y anula lo mapuche y se jerarquizan las creencias de ambas culturas, donde, necesariamente, el cristianismo es mejor y correcto.

Al nombrar la cultura mapuche, aunque sea para negarla, el enunciador la (re)crea, la conforma y con este acto configura un universo referencial nuevo para los oyentes, que se instituye a partir de la inversión de los valores establecidos intraculturalmente: este nuevo mundo es un mundo negado que, para el alocutario, pasa a ser su propia cultura. Si bien las referencias a las formas de vida de los receptores pueden incluir toda clase de comportamientos, fundamentalmente se tratan temas religiosos, en concordancia con el carácter del sermón. Estas menciones están marcadas por la concepción de la demonización de América y por la idea de pecado.

Usamos el concepto alocutario, en el sentido de Ducrot y Todorov (1974), como los receptores que se tienen en cuenta para la producción del discurso. 
2.1.1. El hablante califica las creencias y las prácticas de su auditorio como formas de adoración al Demonio. Así se ve en el fragmento (1), en el cual se equiparan los significados de alhue ('ánima que se incorpora en el cuerpo humano cuando este agoniza', Cfr. Dowling Desmadryl [1973]) y de 'diablo' y 'demonio', por efecto de la contigüidad en la enumeración, con el fin de presentar parte del ideario cristiano a través de una noción que le es familiar al alocutario:

(1) Y por efto todos ellos $\{10\}$ acâ abaxo, por fer tā malos, $\{11\}$ y altiuos, eftà llenos de eno-\{12\}jo, y andan rabiofos, aborre-\{13\}ciendo a Dios, llenos de em\{14\}bidia, haziēdo enemiftades \{15\} con Dios: y a los buenos hō $\{16\}$ bres que obedecen la volun $\{17\}$ tad de Dios, les fon contra-\{18\}rios eftos Angeles malos. E\{\{19\}tos fon los q fe llaman demo\{20\}nios, diablos, y alhues, y abo\{21\}rrecen, y tienen embidia de \{22\} todos los hōbres q fon ima-\{23\}gen de Dios, y fe parecen $\{24\}$ y le han de yr a ver al cielo, $\{25\}$ diziendo ellos, que los hom $\{26\}$ bres han de ver el cielo que $\{27\}$ perdieron ellos (Valdivia 1621: 43; sermón sexto).

De este modo, la cultura mapuche resulta rechazada y descalificada en favor del cristianismo, en un ejercicio en el que todo el mundo referencial de los indígenas pasa por el filtro de la "nueva fe", que lo tergiversa y lo (re)presenta a los mismos protagonistas.

2.1.2. Bajo el concepto de pecado se incorporan las acciones reverenciales de los mapuches y otras prácticas. Lo que el hablante reconoce como hechiceros, en (2), son los 'chamanes' de esta cultura, los machis, que cumplían (y actualmente cumplen) un importante rol religioso y social, ya que también estaban encargados de la sanación corporal (Cfr. Guevara 1911). Con este tipo de recursos, no solo se consigue denostar una práctica indígena, sino que el rechazo se extiende a todas las formas de la cultura:

(2) Nombrar al Pillan al Ma-\{6\}reupuante, al Huecuvoe, $\{7\}$ y reuerenciarlos, creer lo q \{8\} los hechizeron diz, $\bar{e}$, vobe-\{9\}decellos, es tābien pecado. $\{10\}$ Herir a otro hombre, ô ma\{11\}tarle, andar cō la muger a-\{12\}gena, hurtar la hazienda de $\{13\}$ otro, ô de otra manera ha-\{14\}zer daño a alguno, es peca-\{15\}do tambien. Reñir mal a o-\{16\} tro de palabra, y murmu-\{17\}rar del proximo, es tābien \{18\} pecado (Valdivia 1621: 71; sermón noveno).

También se exponen las consecuencias del pecado, entre ellas, la perdición como castigo reservado en el infierno para los mapuches que invocan al pillan (3). No obstante, el locutor ha interpretado sus acciones "reverenciales" como formas equivalentes a las cristianas, mientras que, en realidad, en este caso se trataba de un mecanismo de culto a los antepasados que se representaban en el pillan (Latcham 1924):

(3) $Y\{34\}$ por efto todos los infieles $\{35\}$ fe pierden, $y$ fon quemados $\{36\}$ en el infierno, $y$ todos los q \{37\} con reuerēcia nōbrā al Pillā \{38\} fe perderan en el infierno, y \{39\} feran caftigados fin fin (Valdivia 1621: 24; sermón cuarto).

En estos fragmentos vemos cómo, a partir de la finalidad persuasiva, el mundo indígena se incorpora en el discurso para ser comparado con el cristianismo y se explica siempre a partir de sus bases, en un ejercicio retórico en el que resulta negado, invertido y convertido en el no deber ser, mientras que el cristianismo es el deber ser, 
el bien, lo correcto, el modelo a seguir. Esta incorporación de lo indígena es, por lo tanto, la más clara muestra de la voluntad por inculturar a los receptores.

\subsection{El topos "compartido"}

El topos, que garantiza la validez de los argumentos en función de la conclusión (Anscombre y Ducrot 1994), sugiere la existencia de un mundo cognitivo compartido entre hablante y oyente. Sin embargo, en el discurso analizado, los patrones mentales de los participantes no son iguales, por lo que la relación argumento-conclusión no está garantizada. Sin embargo, el emisor supone que sus receptores tienen su misma visión de mundo, lo que se manifiesta en varios aspectos que organizamos en tres ámbitos: nociones de la cultura europea (occidentalizada y moderna), nociones de la doctrina cristiana (ligada a la anterior) e interpretación de la cultura mapuche.

Esta desregulación en el topos entre hablante-oyente no es exclusiva de esta obra, sino que se manifiesta en todo el proceso de evangelización americana. En definitiva, los misioneros no interpretaron las culturas nativas por sí mismas, sino a través de una óptica moderna -con los consabidos resabios medievales-, que deformó el objeto que interpretaba y lo convirtió en meras expresiones formales, carentes de un contenido que no pudiera ser observado a través del cristianismo. Se trata de una tensión entre diversas formas de entender el mundo y que explican Payàs et al. (2012) respecto de los mediadores lingüísticos coloniales: por una parte los misioneros eran sujetos inquietos por conocer al otro en cuanto actores renacentistas, pero, por otra parte, la tradición medieval los llevaba a rechazar las culturas indígenas y a explicárselas como producto de la acción demoníaca.

2.2.1. Entre los casos relacionados con la concepción europea del mundo del momento, destaca la noción de la temporalidad, una representación de las culturas que opera subliminalmente. En el mundo occidental, el paso del tiempo se ha interpretado por su homogeneidad y regularidad, se han utilizado operaciones cuantitativas para medirlo (Grebe 1987) y se expresa metafóricamente por sucesión lineal. En la tradición cristiana, en concordancia con esta idea, se explica el principio del mundo conocido a través el relato del Génesis, recogido en la Biblia. Cuando el hablante lo expone para enseñarlo y fundamentar su argumentación sobre el poder de Dios (4), supone que los oyentes poseen ese mismo topos: hay un inicio del mundo, hay un principio y un final que se ordenan sucesivamente. Sin embargo, esta idea no está contenida en la cultura mapuche (Latcham 1924), sino que su noción sobre el tiempo se representa metafóricamente en la dinámica propia de la circularidad, con la cual el mapuche se relaciona íntimamente, ya que su misma vinculación con el mapu (la tierra) implica un recorrido temporal, ligado con fuerza al pasado tradicional y a los antepasados (García Barrera 2010):

(4) Efto tambien fabed $q\{21\}$ al principio, defpues $q$ Dios $\{22\}$ crio todas eftas cofas, al cabo $\{23\}$ crio vn hōbre, formado del $\{24\}$ barro de la tierra, fu cuerpo $\{25\}$ y el alma q le auia de dar vi-\{26\}da crio con fu foplo. [...]

$\{p 50\}\{1\} 39$ Efte primero hombre \{2\} llamado Adam, defpues q \{3\} tuuo fer de hōbre fue pue $\{4\}$ to en vn lugar muy bueno $\{5\}$ lleno de deleytes, por el $\{6\}$ mifmo Dios, era 
lugar abū-\{7\}dante, y dōde auia muchas $\{8\}$ cofas para fabor, gozo y re\{9\}galo del hombre no auia a-\{10\}lli enfermedad, ni hābre, ni \{11\} pobreza, ni cāfancio, ni ve$\{12\}$ jez, ni muerte. Diole Dios $\{13\}$ a efte hombre todas las co- $\{14\}$ fas q ay en todo el mundo, $\{15\}$ y el fer feñor del mundo. $\{16\}$ Diole tambien por compa-\{17\}ñera vna muger llamada $\{18\}$ Eua, que le facô de fu cof\{19\}tilla. Eftos dos Adam, y \{20\} Eua, fon los primeros pa-\{21\}dres de todos los hombres \{22\} del mundo, y de los dos fo\{23\} mos todos cafta, y defcen-\{24\}demos.

(Valdivia 1621: 49-50; sermón séptimo)

El discurso se inicia, también, bajo la creencia de que existe un mundo ético compartido o los mismos mecanismos de regulación de las relaciones entre los hombres y de los hombres con las fuerzas superiores. Lo anterior se manifiesta en la idea de la justicia universal, que sostiene la relación pecado/no pecado > castigo/premio:

(5) Elta dize q ay otra vi-\{32\}da defpues de efta de acâ, y $\{33\}$ q aquella vida, nunca fe aca $\{34\} b a, y$ que los que en ef-\{35\}ta vida viuen bien, y a-\{36\}gradan a Dios, tienen bie-\{37\}nes, y defcanso para fiēpre \{38\} en la otra vida, y los q en eโ\{39\}ta vida fon malos, y enojan $\{40\}$ a Dios con pecados, en la o-\{41\}tra vida fon caltigados, con $\{42\}$ penas, $y$ tormentos para $\{43\}$ fiempre.

\{44\} II $\underline{Y}$ efto hermanos es muy \{45\} jufto, y muy conforme a ra\{46\}zon, porque dezidme, no \{47\} es razon que los buenos tē 448$\}$ gà premio del bien q hazé? \{49\} no es razon q los malos ten $\{50\}$ gan caltigo por el mal que $\{51\}$ cometen?

(Valdivia 1621: 2; sermón primero)

2.2.2. Por otra parte, la argumentación se sustenta en la binariedad del pensamiento cristiano, el cual, para comprender el universo y su funcionamiento, interpreta los hechos, fenómenos y la misma existencia humana a partir de dicotomías complementarias $^{6}$, como el dualismo tierra/cielo:

(6) Todas las cofas q eftā $\{8\}$ en el cielo, y tierra, encima $\{9\}$ y debaxo del cielo, y enci$\{10\}$ ma y debaxo de la tierra, $\{11\}$ tienen vn folo Dios, y vn fo $\{12\}$ lo feñor, q es dueño de to- $\{13\}$ das las cofas. No penfeys, ni $\{14\}$ digays q ay vn Dios en el $\{15\}$ cielo, yotro en la tierra (hi \{16\}jos mios.) (Valdivia 1621: 32; sermón quinto).

Los mapuches tenían una idea diferente de la tierra, del mapu, pues los definía como miembros de una cultura, mientras que el concepto cielo no estaba presente en sus creencias (Oyaneder Shultz 1999). El hablante incorpora estas nociones en el discurso, las enseña, pero no comprende los desajustes entre la doctrina cristiana y el pensamiento indígena.

2.2.3. Por último, están los topoi basados en la interpretación de la cultura mapuche que realiza el locutor. El conocimiento compartido parte de su explicación de las creencias religiosas indígenas desde la óptica del cristianismo, lo que produce la desfocalización de las mismas. Con este hecho, presenta al auditorio una práctica reverencial como propia que no corresponde con aquella que se realizaba intraculturalmente, pues los mapuches no tienen "dioses" como los hay en el ideario cristiano, pero el locutor los ha identificado en el pillan y en el totemismo (Cfr. Latcham 1924):

\footnotetext{
De ese modo Núñez Beltrán (1995) explica, por ejemplo, la relación alma/cuerpo.
} 
(7) Dichofo, y bienaue--\{37\}turado el q conoce a Dios, \{38\} y le obedece, y adora, y de \{\{39\} dichados, y defuenturados $\{40\}$ de aquellos hombres locos $\{41\}$ y ciegos, $q$ honran a otras $\{42\}$ cofas, y no conocen a Dios, $\{43\}$ ni le obedecen, ni reueren $\{44\}$ cian. No aueys verguença $\{45\}$ de q adorauades al Pillan, \{46\} y Huecuvoe, como a Dios, \{47\} no fiendo dignos de tal ado 48 ; racion, y reuerencia (Valdivia 1621: 35; sermón quinto).

En definitiva, el hablante no se percata de que las prácticas intraculturales se explican por sí mismas, en el seno de la comunidad, e interpretó la forma mapuche de percibir el mundo a través de la suya. De este modo, dio paso a una invisibilización de las diferencias culturales que afectó el proceso persuasivo, dando como resultado un discurso falible en su argumentación.

\subsection{La cultura mapuche como autoridad}

Según Perelman y Olbrechts-Tyteca (1989 [1958]), el argumento de autoridad está condicionado por el prestigio, ya que con él se utilizan los "actos o juicios de una persona como medio de prueba a favor de una tesis" (470). En el sermonario se usa la autoridad de los alocutarios, quienes, supuestamente, han pasado ya por un proceso de catequesis que se complementa con los sermones. Al menos así lo indicó el III Concilio Provincial de Lima, cuando se imprimió el Tercero catecismo, en cuyo Proemio se juzga como necesario que la doctrina que se ha ofrecido previamente se presente ahora

[...] a los Indios en tal modo, q no folo la percibieffen, y formaffen concepto de eftas verdades chriftianas: pero tābien fe perfuadieflen a creerlas, y obrarlas como fe requiere para fer falvos. Y para efto es neceffario differēte eftilo, y ha de fer como fermō o platica del predicador, y tal que enfeñe, y agrade, y mueua a los oyētes, para que afsi recibā doEtrina de Dios y la guardē (Concilio Provincial de Lima 1585: 5v).

En ese marco, se ve a los indígenas como neófitos del cristianismo, pero cristianos, al fin y al cabo, por lo que se despliegan estrategias que apelan a su conocimiento (aunque rudimentario) de las verdades de la fe:

(8) Primeramente, her-\{26\}manos, bien fabeys q fois \{27\} hombres como yo, y como $\{28\}$ los demas, y q todos los hō-\{29\}bres aca détro de efte cuer-\{30\}po q veys, tenemos vna al-\{31\}ma, q aung no la vemos, por \{32\}, no es de carne, ni de huel\{33\}\{o, como el cuerpo, pero cō $\{34\}$ ella viuimos, y hablamos $\{35\}$ queremos, fabemos, y pē $\mathrm{e} a\{36\}$ mos, y hazemos muchas co\{37\}\{as: y en faliendo elta alma $\{38\}$ del cuerpo, q es quādo mue $\{39\}$ re vn hōbre, luego el cuer-\{40\}po queda lin fentido, y fin $\{41\}$ menear $\{e, c o m o$ vna pie-\{42\}dra, ô vn pedaço de tierra (Valdivia 1621: 1; sermón primero).

En lo anterior se presupone que los oyentes comparten algunos principios ideológicos con el locutor, por lo que se los incluye bajo el mismo concepto: hombres. Es un movimiento retórico que, al enlazar, rechaza las diferencias, de modo que niega el ser mapuche para incorporar a los sujetos indígenas en la nueva cosmovisión.

\section{LA CAPACIDAD COGNITIVA MAPUCHE EN LA COMPRENSIÓN DEL DISCURSO}

Si el Proemio del Tercero catecismo informa sobre la necesidad de "acomodación" a un público que se consideraba como menos capacitado que los españoles para recibir la 
Palabra de Dios, en Valdivia (1621) hay un segundo proceso de acomodación a un público aún menos capaz. Es decir, hay una adecuación del discurso a la capacidad cognitiva que se le adjudica al oyente determinada por su pertenencia cultural. Por ello, se usan la repetición, la reformulación y los argumentos que se construyen por concreción y ejemplificación.

\subsection{Repetición}

Consiste en la reaparición de un elemento lingüístico que ya ha sido utilizado (Garcés Gómez 2004). En nuestros textos se usa con el fin de crear paralelismos, reforzar la conclusión y facilitar el avance informativo. Estas funciones se cumplen siempre en la orientación hacia la finalidad argumentativa del discurso (cfr. Cancino Cabello 2011a), ya que la repetición se utiliza como una forma de "asegurar" la recepción del contenido por parte de un público al que se le atribuye una capacidad cognitiva inferior, por lo que es necesario volver sobre lo dicho.

3.1.1. Con este recurso se crean estructuras paralelas que otorgan unidad al enunciado y dosifican la información como parte de una estrategia explicativa. Gracias a lo anterior se explicita la doble dimensión pedagógica-argumentativa de los sermones: facilita la comprensión y la memorización. La repetición se presenta cuando se trata de la conclusión y se construye en torno a dos segmentos que quedan, de esa forma, cohesionados:

(9) [...] dio fer $\{5\}$ a los Angeles, cuyos exer-\{6\}citos no fe pueden contar $\{7\}$ por fer tantos, no fon como $\{8\}$ nueftro cuerpo ellos, q no $\{9\}$ tienen carne ni hueffos, ni $\{10\}$ fon vifibles cō nueftros o-\{11\}jos corporales: fon efpiritu $\{12\}$ como lo es nueftra alma: pe\{13\}ro de diuerfa manera fon ef\{14\}piritu ella, y ellos, q nuef-\{15\}tra alma pide cuerpo, por $\{16\}$ fer como fomos hōbres no-\{17\}\{otros, que la mitad de nue $\{18\}$ ftro fer humano, es el cuer-\{19\}po, y la otra mitad es el al-\{20\}ma inuifible: pero de diuer\{21\}\{a manera fon efpiritu los \{22\} Angeles, q no piden cuer-\{23\}po, fu fer efpiritual no fe di $\{24\}$ uide, no ay mitad en ellos, $\{25\}$ todo fu fer entero, es efpiri $\{26\}$ tu (Valdivia 1621: 41; sermón sexto).

3.1.2. La reafirmación de la conclusión también se logra por la remisión anafórica de más de un segmento, en una forma de repetición que se vale de los recursos sintácticos. En (10), se establece una correlación entre los infinitivos verbales (en función sustantiva) y una oración atributiva en la que se retoman como sujetos. Esta estrategia se usa para explicar el concepto de pecado, de relevancia en la evangelización de América y, particularmente, en Valdivia (1621):

(10) Todo vueftro mal es $\{18\}$ el pecado, fi quereys faber $\{19\}$ que cofa es pecado: oyd, $y$ \{20\} lo fabreys. 1 No obede-\{21\}cer lo que Dios manda, y fe $\{22\}$ guir folo nueftro gufto, ef-\{23\}to es pecado. THazer $\{24\}$ vueftra voluntad, y no la $\{25\}$ de Dios, ni cumplir lo que \{26\} manda, efto es pecado. $\{27\}$ Hurtar adulterar, jurar $\{28\}$ falso, adorar al Pillan, y al \{29\} Huecuvoe, hazer daño a \{30\} otro, efto es pecado (Valdivia 1621: 7; sermón segundo).

3.1.3. La repetición contribuye al avance informativo (Garcés Gómez 2004) y es un recurso de cohesión. Al volver sobre un aspecto del texto a partir de la reiteración de 
una forma se otorga cierto sentido circular macroestructural al enunciado, de modo que se acerca a la oralidad. Sirve para mantener la línea informativa y ampliarla hacia otros tópicos del mismo asunto:

(11) Con efta Fè los fantos $\{38\}$ admirablemente hizieron $\{39\}$ marauillas, muchos dieron $\{40\}$ vifta a ciegos, falud a enfer $\{41\}$ mos, vida a muertos, y co-\{42\}mo quien puede mādar māa 43$\}$ dauan a la mar, y al Sol, y a \{p26\}\{1\} todas las cofas, porq todas $\{2\}$ eftauan fugetas a la palabra $\{3\}$ diuina.

\{4\} 8 Con efta palabra de \{5\} Dios, y con efta fu Fè, todo $\{6\}$ el mundo fe boluio a Dios, $\{7\}$ y fe trocaron fus coraçones $\{8\}$ y muchos Reyes, $y$ feñores, $\{9\}$ muchos fabios, $y$ poderofos, $\{10\}$ todos eftos reuerenciaron $\{11\}$ con fugecion la palabra de $\{12\}$ Dios, y la Fè en IefuCgrifto.

(Valdivia 1621: 25-26; sermón cuarto)

\subsection{Reformulación}

El proceso de reformulación requiere de dos segmentos: se considera en el segundo lo dicho en el primero, pero se presenta el contenido de manera distinta (Herrero Ingelmo 2007), dando origen a un nuevo enunciado (Fuentes Rodríguez 2004). Es, por ello, un valioso recurso didáctico en los sermones, ya que facilita el aprendizaje de la doctrina al permitir que esta reaparezca, de modo que lo "esencial de la fe" quedará "grabado" en la mente de un receptor cuya capacidad cognitiva no le permite el aprendizaje con una sola mención, a juicio del hablante.

En los textos hallamos fórmulas aún no estandarizadas cuyo valor reformulativo se adquiere del contexto ${ }^{7}$. Además, hemos encontrado casos en que este sentido no está "anunciado" por formas especiales, sino que se deduce de los segmentos contiguos. Siguiendo a Gülich y Kotschi (1995), distinguimos entre la reformulación parafrástica y la no parafrástica, cuyo uso en los sermones está motivado por la dimensión pedagógica del tipo textual.

3.2.1. En el primer tipo, los segmentos en relación son semánticamente equivalentes y el segundo de ellos presenta nuevas informaciones que motivan su aparición (Camacho Adarve 2009). Este recurso ha sido identificado por Perelman y OlbrechtsTyteca (1989 [1958]) como una forma de corrección progresiva, explicación cercana a nuestro corpus, ya que no solo se vuelve hacia atrás, sino que de esa manera también avanza la información.

Por otra parte, con esta forma de reformulación, el hablante deja constancia en el discurso de la importancia del segmento, lo que en sí mismo constituye una muestra de su interés por su significado y, al mismo tiempo, por dejarle en claro su relieve al oyente (Camacho Adarve 2005). En ese sentido, como ocurre en los sermones, es un recurso de orientación para la interpretación: esta información ha de ser retenida por el receptor.

En los casos hallados, la relación se obtiene del contexto (no hay marcas específicas), pese a lo cual la información del segundo segmento se focaliza. Con ello, además, los contenidos se presentan circularmente, insertando el enunciado

En general, los marcadores de reformulación no se gramaticalizaban por completo en la época del sermonario (Cfr. Pérez-Salazar Resano 2006). 
completo en el ámbito de la oralidad, de modo que este tipo de reformulaciones muestra otra dimensión que buscan los textos (de acuerdo con las directrices del III Concilio de Lima): ser modelos de cómo se convence, cómo se argumenta, pero no solo en lo escrito, sino también (y fundamentalmente) en lo hablado.

Dicha clase de reformulación recurre, en el sermonario, a estructuras con las cuales se presenta el mismo contenido, pero "con otras palabras". Aquí aparecen dos posibilidades: la secuencia <segmento (afirmativo) $1+$ segmento (negativo) $2>$, en la que se coordinan los miembros (12), o la secuencia <segmento (negativo) $1+$ segmento (afirmativo) 2> (13):

(12) Vn Dios ay no mas, y no ay \{19\} otro, el mifmo Dios lo di-\{20\}xo a fu gente de Ifrael con $\{21\}$ eftas palabras. Oyeme If- $\{22\}$ rael, q tu Señor Dios, vno $\{23\}$ folo es (Valdivia 1621: 33; sermón quinto).

(13) Nueue mefes, eftuuo \{37\} en el vientre de fu Madre, \{38\} como los demas niños, y $\{39\}$ defpues nacio en vna ciu-\{40\}dad llamada Bathlem, mila\{41\} grofamente, porque quan-\{42\}do le pario, y defpues del \{43\} parto, no fe diuidio fu virgi 444 inal cuerpo, entero fe que-\{45\}dô, de la manera que eftaua $\{46\}$ la Virgen Santa Maria an-\{47\}tes del parto, que no auia $\{48\}$ conocido varon, afsi eftu\{49\}uo en el parto (Valdivia 1621: 16; sermón tercero).

3.2.2. En la reformulación no parafrástica, el nuevo segmento implica una modificación en la perspectiva enunciativa con respecto del anterior y la separación entre ambos es de grado. Los segmentos no son semántica ni pragmáticamente equivalentes, sino que el segundo introduce algunas variaciones con respecto del primero que acarrean diferencias funcionales (Cfr. Bach Martorell 2009). En los sermones, estas modificaciones impactan sobre la interpretación del discurso a través de la síntesis de los contenidos y la designación de lo que se ha descrito.

En primer lugar, el resumen presenta los contenidos ya expresados, pero condensados. Es frecuente que en este caso aparezcan índices de reformulación, como en (14), donde hallamos o de otra manera, una forma libre que no se había fijado en el idioma en la época del sermonario ${ }^{8}$ y en la cual se sobreentiende un verbo enunciativo (o dicho de otra manera). Para asegurar la relación entre los segmentos, el hablante introduce una forma de adición (el adverbio también) en el segundo; la conjunción $o$ se usa por su valor en la unión de elementos equivalentes:

(14) Preguntareyfme aca $\{47\}$ fo $q$ cofa es pecado, y co-\{48\}mo fabreys $q$ eftays en $p e-\{p 71\}$ $\{1\}$ cado. En pocas palabras os $\{2\}$ lo enfeñare, qualquier cofa $\{3\}$ q es contraria a lo $q$ Dios $\{4\}$ manda, es lin duda pecado. $\{5\}$ Nombrar al Pillan al Ma-\{6\}reupuante, al Huecuvoe, $\{7\}$ y reuerenciarlos, creer lo $q\{8\}$ los hechizeron dize, y obe-\{9\}decellos, es tābien pecado. $\{10\}$ Herir a otro hombre, ô ma $\{11\}$ tarle, andar cō la muger a-\{12\} gena, hurtar la hazienda de $\{13\}$ otro, ô de otra manera ha-\{14\}zer daño a alguno, es peca-\{15\}do tambien (Valdivia 1621: 70-71; sermón noveno).

La reformulación se presenta, también, como denominación metaléxica de un elemento que ha sido mencionado inmediatamente antes en el discurso. $\mathrm{Su}$ 
función se ubica en la dimensión didáctica del sermón, puesto que, con la acción de nombrar, se enseña. En su inclusión es posible diferenciar dos oyentes: los indígenas y los misioneros jesuitas que usarán Sermón en lengua de Chile como modelo de predicación ${ }^{9}$.

Ante los mapuches como alocutarios, el uso de la denominación sirve para describir conceptos abstractos de la tradición cristiana sin correspondencia en el mapudungun (15). Se trata de formas que se realzan frente a otras que no son designadas y que evidencian la responsabilidad y evaluación del locutor en el proceso de enseñanza:

(15) Fueron fus $\{23\}$ almas detenidas en prifion $\{24\}$ en otra parte debaxo de la $\{25\}$ tierra, llamada Limbo, y $\{26\}$ hafta q llegaffe el Señor Ie-\{27\}fu Chrifto a efte litio a li-\{28\}brarlos a ellos de alli, auian $\{29\}$ de eftar alli, y hafta que el $\{30\}$ Señor fubiefle a los cielos, $\{31\}$ y fueffe a abrir los que efta 32$\}$ uan cerrados por el pecado $\{33\}$ de Adam, $y$ fubieffen to-\{34\}dos con el al cielo, auian de \{35\} eftar alli (Valdivia 1621: 57; sermón séptimo).

Por otra parte, el hablante denomina conceptos pertenecientes a la cultura mapuche, con la finalidad de que los jesuitas los aprendan y hagan más efectiva su prédica, aunque esta enseñanza no deja de ser etnocéntrica y poco tiene que ver con el significado que los indígenas les daban a los términos. En (16) se explica el concepto pillan como volcán ${ }^{10}$ a partir de una representación de las fuerzas de la naturaleza (Cfr. 2.1.2.):

(16) Vofo-\{p36\}\{1\}tros en el fer de hombres, $\{2\}$ foys mas q el Pillan (q es el $\{3\}$ Volcāa $)$ y mas, q lo q llamays $\{4\}$ Huecuvoe, Dios folo es dig $\{5\}$ no de fer adorado, y refpe-\{6\} Etado verdaderamēte, y vo $\{7\}$ fotros le quitaftes la honra $\{8\}$ deuida a Dios, es lamenta-\{9\}ble cofa (Valdivia 1621: 35-36; sermón quinto).

Este ejercicio de traducción se ofrece a modo de inciso, pues este tipo de receptor (los misioneros) se construye como tal solo en cuanto utilizará los sermones como modelos para la prédica, pero los alocutarios son los mapuches.

\subsection{Argumentos por concreción y ejemplificación}

En el sermonario, la concreción y la ejemplificación se utilizan con el fin de presentar los argumentos. Constituyen un recurso didáctico que permite actualizar los contenidos de la doctrina a las particularidades de un alocutario que el hablante percibe como compuesto por hombres incapaces de comprender la abstracción, de modo que el paso a lo concreto ofrece la posibilidad de acceder a ella, en el entendido de que lo real y perceptible es más cercano para los oyentes que lo abstracto. Ahora bien, concreción y ejemplificación no son sinónimos, sino que se diferencian en que la primera implica un movimiento de especificación de lo general a lo particular, mientras que la segunda ilustra lo dicho con un caso elegido aleatoriamente de los muchos disponibles, en una relación de inclusión-explicación (Fuentes y Alcaide 2002).

Estamos ante un caso de poliacroasis: distinción de varios oyentes "que realizan múltiples actos de audición/ interpretación" (Albaladejo Mayordomo 2000: 15). Cada uno posee unas determinadas características ideológicas, sociales y culturales, a partir de las cuales se adecua el discurso. 
En la oratoria, este movimiento argumentativo fue importante en la predicación popular, debido a la baja calidad que se le asignaba al auditorio (Pérez 2011). De hecho, el Proemio del Tercero catecismo recomienda a los predicadores el uso de ejemplos con los indígenas, cuyos entendimientos "cortos y tiernos" (Concilio Provincial de Lima 1585: 3r) no están capacitados para captar temas abstractos, por lo que aquellos sacerdotes que tratan asuntos elevados los ofuscan y confunden.

3.3.1. La concreción en el sermonario se presenta mediante la focalización de los segmentos introducidos por formas conectivas que mantienen un valor modal y mostratorio, como en (17) (así vemos que..., así...), donde aparecen casos particulares de la justicia universal:

(17) [...] dezidme, no \{47\} es razon que los buenos tē $\{48\}$ ga premio del bien q hazēe $\{49\}$ no es razon q los malos ten $\{50\}$ gan caltigo por el mal que $\{51\}$ cometen?

\{p3\}\{1\} 8 II Afsi vemos que lo \{2\} haze vn Indio con fus hi-\{3\}jos en fu cafa, que al bue hi-\{4\}jo le honra, y haze bien, y \{5\} al malo, y defobediente, \{6\} fe enoja con el, vle caftiga.

\{7\} 9 I A/si tambien los feño\{8\}res que mandan, y rigen los \{9\} pueblos, honran, y hazen $\{10\}$ bien a los que firuen, $y\{11\}$ obedecen, y a los foberuios $\{12\}$ y malos, los prenden, $y$ caf\{13\}tigan. $10 \square$ Porque es $\{14\}$ efto afsi? porque la virtud $\{15\}$ merece premio, y el peca-\{16\}do merece caftigo.

(Valdivia 1621: 2-3; sermón primero)

En (18), se manifiesta una doble concreción de lo enunciado en la conclusión: quiénes se perderán y quiénes se salvarán. El fragmento que contiene el sentido de lo concreto está introducido por el conector pues y el verbo de percepción general notad, que dan cuenta de la voluntad del hablante por obtener la atención del interlocutor sobre estos segmentos:

(18) Afsi que Dios fien-\{2\}do bueno, y jufto, como lo \{3\} es, y padre de todos los hō $\{4\}$ bres, justo es que a los bue-\{5\}nos hijos que obedecen a $\{0\}$ Dios, y guardan fuley, les $\{7\}$ de bienes, $y$ a los malos, $y\{8\}$ defobedientes les de males $\{9\}$ y penas. INo es bueno $\{10\}$ efto? Todos direys: Afsi es $\{11\}$ padre, no ay que dudar.

$\{12\} 15$ q Pues notad aora bie $\{13\}$ que aca ay en todas partes $\{14\}$ muchos malos hombres $q\{15$, roban a otros, $y$ les toman $\{16\}$ fus mugeres, $y$ fon fober- $\{17\}$ bios, $y$ hazen otros gene-\{18\}ros de pecados, y eftā muy $\{19\}$ ricos, y cōtentos. I Pues $\{20\}$ efto hafe de paffar afsi fin $\{21\}$ caftigo de tantos pecados? [...]

$\{34\} 16$ Pero al contrario los \{35\} buenos que aca viuian bien \{36\} y eran pobres, $y$ enfermos, $\{37\}$ y lleuauan cō paciencia los \{38\} agrauios que otros les ha-\{39\}zian, y ellos hazian bien a $\{40\}$ todos, y cumplian lo que $\{41\}$ Dios manda en la otra vida $\{42\}$ que fera de eftos? no auia $\{43\}$ de auer quien les agrade- $\{44\}$ cieffe eftos bienes que hi-\{45\}zieron, afsi fe auia de paf-\{46\}far efto? No por cierto $\{47\}$ que por ello es gran verdad $\{p 5\}\{1\}$ que ay otra vida a donde $\{2\}$ Dios pagara a los buenos, $y\{3\} \mathrm{fe}$ dexara ver dellos para $q\{4\}$ tengan gozo eterno

(Valdivia 1621: 4-5; sermón primero)

3.3.2. Por otra parte, están los enunciados que ejemplifican una generalidad. Para Lausberg (1966: 349), el exemplum "tiene una fuente fuera de la causa", cuya relación, basada en la semejanza, se explica por inducción. 
Un tipo específico de ejemplificación en los sermones es el modelo, con el cual no solo se fundamenta un aspecto general, sino que también se incita a la imitación de determinadas conductas (Perelman y Olbrechts-Tyteca 1989 [1958]). Tiene una dimensión histórica en el relato de los acontecimientos que conducen a la institucionalidad de la Iglesia, en el cual la actuación de los personajes tiene un valor testimonial y funciona como el deber ser. En el fragmento (19), se presentan, en correlación, los mártires como modelos:

(19) Auia otros varones $\{2\}$ buenos en la Iglefia q bufca $\{3\}$ uan los defiertos defpobla-\{4\} dos para viuir folos, y no te $\{5\}$ ner conuerfacion cō nadie $\{6\}$ y alli por Iefu Chrifto fe a-\{7\}tormentauan, y açotauan, $y\{8\}$ dia, y noche ocupauan con $\{9\}$ Dios. Tal fue S. Antonio, $y\{10\}$ otros como el.

$\{11\} 11$ ๆ Otros a imitaciū de $\{12\}$ los Apoftoles, dexauan fus $\{13\}$ haziendas, y parientes por $\{14\}$ IefuChrifto, y muchos jun $\{15\}$ tos en vna cafa viuian con $\{16\}$ mucho orden, $y$ concierto, $\{17\}$ imitauan en fu vida la vida $\{18\}$ de Iefu chrifto. Tal fue Sā $\{19\}$ Benito, S. Domingo, S. Frāa $\{20\}$ cifco, y S. Ignacio.

$\{21\} 12$ Otros padres auia $q\{22\}$ fiendo maeftros de todos $\{23\}$ los hombres a todos enfeña $\{24\}$ uan, y los fecretos de las co $\{25\}$ fas diuinas los declarauan, $\{26\}$ y en libros que efcriuieron $\{27\}$ nos dexaron efcritas fus de\{28\}claraciones-Eftos fe llama-\{29\} uan DoEtores. Tal fueron \{30\} S. Aguftin, S. Ambrofio, S. \{31\} Geronymo.

$\{32\} 13 \llbracket$ Mugeres tambien $q\{33\}$ no conocierō varones ente $\{34\}$ ras en fus cuerpos huuo fiē $\{35\}$ pre q murierō por chrifto. $\{36\}$ Tal fue S. catalina, y S. Ynes.

(Valdivia 1621: 64; sermón octavo)

Gracias a este este ejercicio, los cristianos se constituyen en el grupo de prestigio, mientras que los mapuches, ubicados en un nivel inferior de la escala relacional, deben abandonar su cultura para seguirlos. Con lo anterior, el hablante mantiene el paradigma de un nosotros situado en el plano de lo correcto.

\section{Conclusiones}

Sermón en lengua de Chile es un texto que se elabora para facilitar la evangelización de los mapuches, identificados como los alocutarios de la obra. Dicha determinación se expresa en una serie de recursos argumentativos mediante los cuales el emisor da cuenta de una voluntad por acomodar o adecuar el discurso a ese público particular. Lo anterior se explicita en el título del sermonario y se manifiesta, por ejemplo, en la traducción de los textos al mapudungun. Con esta adecuación a partir de la diferenciación cultural, el hablante construye un sujeto-instancia enunciativa doblemente determinada: por el ser mapuche y, como consecuencia de lo anterior, por tener una capacidad mental "menor" o, al menos, "diferente".

La adaptación a la cultura (traducción a/desde la cultura) implica concebir a los oyentes como miembros de un exogrupo, cuyas ideas (en especial, del ámbito religioso) tienen una correlación en el plano de los comportamientos. Por lo anterior, se incluyen argumentos que hacen referencia a prácticas y creencias mapuches o, más bien, a la interpretación (y/o manipulación) que ha hecho de ellas el emisor desde la lógica del cristianismo. Del mismo modo, el discurso se elabora a partir de una serie de creencias compartidas que, en realidad, no son equivalentes en la relación intercultural, pero que son objeto de un proceso de invisibilización con el 
fin de asimilar la cultura mapuche a la hispana. Recordemos, en este sentido, que la evangelización no solo perseguía convencer sobre la primacía del cristianismo, sino que también pretendía una modificación en los comportamientos grupales e individuales de las comunidades a las que se enfrentaba, con el fin de implantar una moral hispana, ordenada y jerarquizada ${ }^{11}$.

El desajuste entre las prácticas mapuches efectivas y la interpretación/ manipulación del locutor se puede comprobar con la reconstrucción etnohistórica mapuche y la historia externa de la obra. Por ende, afirmamos la necesidad de estudiar los textos del pasado desde una óptica interdisciplinaria, ya que este ejercicio nos permite explicarlos en sus condiciones de producción e identificar su tradición de discurso.

Por otra parte, de acuerdo con los recursos usados, el hablante supone que la pertenencia cultural determina la capacidad cognitiva del alocutario para comprender el discurso, de tal modo que esta resulta inferior a la de los miembros de su endogrupo (cristianos, españoles...). En consecuencia, utiliza estrategias que "aseguran" la persuasión y el aprendizaje de la doctrina.

En lo anterior vemos que las ideas de los “defensores del indio", en cuya tradición se ha insertado a Luis de Valdivia, nunca escaparon de la lógica de la colonización y, en el fondo, de la dominación, sino que pusieron en discusión sus formas de abuso, sin cuestionar el estatuto mismo de la presencia española en el continente americano. Sostenemos también que los textos catequéticos se utilizaron como herramientas de una evangelización que buscaba la aculturación con un doble fin, que, aunque evidente, no siempre se explicita: el ser (hacerse) cristiano implicaba dejar de ser indígena.

\section{OBRAS CITADAS}

\section{Fuente primaria}

Valdivia, Luis de. 1621. Sermon en lengva de Chile, de los mysterios de nvestra santa fe catholica, para dedicarla a los indios infieles del reyno de Chile, dividido en nveve partes pequeñas, acomodadas a fu capacidad. Valladolid: [Jeronimo de Murillo]. Biblioteca Nacional de Chile, Sala Medina, signatura SM 167.2 (microfilm). En línea; disponible en: http://www.memoriachilena.cl/archivos2/pdfs/MC0013037.pdf. (Consulta: 09/10/2009).

\section{Fuentes secundarias}

Aedo Fuentes, María Teresa. 2005. "El doble discurso de la frontera: los textos catequísticos de padre Luis de Valdivia". Acta Literaria 30: 97-110.

Agustín, San. 1969 [396-397/426-427]. "Sobre la Doctrina Cristiana”. Obras de San Agustín. De la Doctrina Cristiana. Vol. XV. Ed. Balbino Martín. Madrid: BAC. 43-285. 1998 [400]. "La catequesis a principiantes". Obras completas de San Agustín. Escritos varios 1. Vol. XXXIX. Ed. Lope Cilleruelo. Madrid: Biblioteca de Autores Cristianos. 425-534.

Albaladejo Mayordomo, Tomás. 2000. "Polifonía y poliacroasis en la oratoria política.

Según Lowry (1988), la idea de que los españoles eran los portadores de esta buena policía fue la justificación de toda la conquista. 
Propuestas para una retórica bajtiniana”. Retórica, politica e ideología. Desde la Antigüedad hasta nuestros días. Vol. III. Eds. Francisco Cortés Gabaudan, Gregorio Hinojo Andrés y Antonio López Eire. Salamanca: Logo. 11-21.

Amunátegui Solar, Domingo. 1934. Jesuitas, gobernantes, militares y escritores. Santiago de Chile: Ercilla.

Anscombre, Jean-Claude y Oswald Ducrot. 1994. La argumentación en la lengua. Madrid: Gredos.

Bach Martorell, Carme. 2009. "La reformulación del discurso en español en comparación con el catalán. Estudio contrastivo de los marcadores de reformulación". La reformulación del discurso en español en comparación con otras lenguas (catalán, francés, italiano, inglés, alemán e islandés). Dir. María Pilar Garcés. Madrid: Universidad Carlos III; Boletín Oficial del Estado. 37-66.

Briscoe, Marianne G. 1992. "Artes Praedicandi”. Tipologie des sources du Moyen Âge Occidental 61. Dir. Leopold Genicot. Turnhout: Brepols. 76-82.

Bustos Tovar, J. J. de. 2000. "Texto, discurso e historia de la lengua". Revista de Investigación Lingüistica 2(III). En línea; disponible en http://www.vallenajerilla.com/berceo/ bustostovar/discurso.htm. (Consulta: 25/10/2009).

Camacho Adarve, María Matilde. 2005. "La repetición como procedimiento reformulador en el discurso oral”. Estudios sobre lo metalingüistico (en español). Eds. Manuel Casado Velarde, Ramón González Ruiz y Óscar Loureda Lamas. Frankfurt am Main: Peter Lang. 67-92.

2009. Análisis del discurso y repetición: palabras, actitudes y sentimientos (Anejos 5 de Oralia). Madrid: Arco/Libros.

Cancino Cabello, Nataly. 2011a. "Estructura argumentativa de sermones utilizados en la evangelización del pueblo mapuche (siglo XVII)". Nuevas líneas de investigación en el estudio diacrónico de la lengua española. Coord. Angustias Beas Teruel. Palma de Mallorca: Universitat de les Illes Balears. 23-34.

. 2011b: "Los textos no contemporáneos del español de América. Algunas reflexiones sobre lingüística e interdisciplinariedad". Cuadernos de la Alfal 2: 186-195. En línea; disponible en http://mundoalfal.org/sites/default/files/revista/02_cuaderno_015.pdf. (Consulta: 10/10/2013).

2012. "El "Tercero Catecismo" del III Concilio de Lima: un modelo textual para la evangelización americana". Comunicación presentada en el $9^{\circ}$ Congreso Internacional de la Asociación de Historia de la Lengua Española (Cádiz, España, 10-14 de septiembre de 2012).

Concilio Provincial de Lima. 1585. Tercero Cathecismo y exposicion de la Doetrina Christiana, por Sermones. Para qve los cvras y otros miniftros prediquen y enfeñen a los Yndios y a las demás perfonas. Conforme a los que en el sancto Concilio Prouincial de Lima fe proueyo. Impresso con licencia de la Real Audiencia. Cuidad de los Reyes [Lima]: Antonio Ricardo.

Contreras Seitz, Manuel. 2013. "Textos chilenos del período colonial: ediciones, proyectos y perspectivas”. Boletín de Filología XLVIII/1: 53-80. En línea; disponible en http://www. scielo.cl/pdf/bfilol/v48n1/art03.pdf. (Consulta: 24/08/2013).

Díaz Blanco, José Manuel. 2010. Razón de Estado y buen gobierno. La Guerra Defensiva y el imperialismo español en tiempos de Felipe III. Sevilla: Universidad de Sevilla.

Dowling Desmadryl, Jorge. 1973. Religión, chamanismo y mitología mapuches. Santiago de Chile: Universitaria.

Ducrot, Orwald y Tzvetan Todorov. 1974. Diccionario enciclopédico de las ciencias del lenguaje. Buenos Aires: Siglo XXI.

Foerster, Rolf. 1994. Historia de la evangelización del pueblo mapuche. Santiago de Chile: Centro Ecuménico Diego Medellín. 
1996. Jesuitas y mapuches: 1593-1767. Santiago de Chile: Universitaria.

Fuentes Rodríguez, Catalina, 2004. "Enunciación, aserción y modalidad, tres clásicos". Anuario de Estudios Filológicos XXVII: 121-145.

. 2009. Diccionario de conectores y operadores del español. Madrid: Arco/Libros.

Fuentes Rodríguez, Catalina y Esperanza Alcaide Lara. 2002. Mecanismos Lingüísticos de la persuasión. Madrid: Arco/Libros.

Garcés Gómez, María Pilar. 2004. "La repetición: formas y funciones en el discurso oral". Archivo de Filología Aragonesa LIX-LX: 437-456.

García Barrera, Mabel. 2010. "La construcción del relato mítico ancestral en el arte y la poesía mapuche actual”. Papeles de trabajo 20: 43-56. En línea, disponible en http://www. scielo.org.ar/pdf/paptra/n20/n20a05.pdf. (Consulta: 28/11/2012).

Grebe, María Ester, 1987. "La concepción del tiempo en la cultura mapuche". Revista Chilena de Antropología 6: 59-74.

Guevara, Tomás. 1911. Folklore araucano. Refranes, cuentos, cantos, procedimientos industriales, costumbres prehispánicas. Santiago de Chile: Cervantes.

Gülich, Elisabeth y Thomas Kotschi. 1995. "Discourse Production in Oral Communication. A Study Based on French". Aspects of oral communication. Ed. Uta Quasthoff. Berlin: Mouton de Gruyter. 30-66.

Herrero Ingelmo, José Luis. 2007. "Cómo surgen los conectores: los reformuladores id est, esto es, es decir". Revista de lexicografía XIII: 45-54.

Kosel, Ana Carina. 1997. "Los sermones de Valdivia: distribución de lugares, didáctica y polémica en un testimonio del choque de dos culturas". Anuario de Estudios Americanos 54/1: 229-244.

Latcham, Ricardo E. 1924. "La organización social y las creencias religiosas de los antiguos araucanos". Publicaciones del Museo de Etnología y Antropología de Chile. Vol. III. Santiago de Chile: Cervantes. 245-868.

Lausberg, Heinrich. 1966. Manual de retórica literaria. Tomo I. Madrid: Gredos.

Lowry, Lyn. 1988. "Religión y control social en la colonia: el caso de los indios urbanos de Lima, 1570-1620". Allpanchis XX/32: 11-42.

Medina, José Toribio. 1918. "Noticia Bibliográfica, Histórica y Etnográfica”. Fragmentos de la Doctrina Cristiana en la lengua Millcayac del P. Luis de Valdivia únicos que hasta ahora se conozcan sacados de la edición de Lima de 1607 y reimpresos en facsímil con un prólogo. Ed. José Toribio Medina. Santiago de Chile: Elzeviriana. IX-XXXVI.

Mires, Fernando. 2006. La colonización de las almas. Misión y conquista en Hispanoamérica. Buenos Aires: Libros de la Araucaria.

Murphy, James J. 1989. "El fin del mundo antiguo: la segunda sofística y San Agustín". Sinopsis histórica de la retórica clásica. Ed. James J. Murphy. Madrid: Gredos. 246-257.

Núñez Beltrán, Miguel Ángel. 1995. "Predicación, pautas de conducta y consolación en el siglo XVII". Anuario de investigaciones Hespérides 3/1: 339-355.

Oyaneder Schultz, Liliana. 1999. Iconografía mapuche. Santiago de Chile: LOS.

Payàs, Gertudris, José Manuel Zavala y Mario Samaniego. 2012. “Al filo del malentendido: el Padre Luis de Valdivia y la mediación lingüística". Historia 45/1: 69-90.

Perelman, Chaïm y Lucie Olbrechts-Tyteca. 1989 [1958]. Tratado de la argumentación. La nueva retórica. Madrid: Gredos.

Pérez, Manuel. 2011. Los cuentos del predicador. Historias y ficciones para la reforma de costumbres en la Nueva España. Madrid: Universidad de Navarra; Iberoamericana; Vervuet; Bonilla Artigas.

Pérez-Salazar Resano, Carmela. 2006. "Datos para la historia de algunos marcadores de reformulación”. Actas del VI Congreso Internacional de Historia de la Lengua Española. Tomo III. Eds. José Jesús de Bustos Tovar y José Luis Girón Alconchel. Madrid: Arco/ Libros. 2838-2854. 
Ramón, José Armando de. 1961. "El pensamiento político-social del P. Luis de Valdivia". Boletín de la Academia Chilena de la Historia XXVIII/64: 85-106.

Ricard, Robert. 1964. Estudios de literatura religiosa española. Madrid: Gredos.

Urrejola D., Bernarda. 2011. "'Este sermón es moneda de todo valor': la circulación de un saber de buena ley en la oratoria sagrada novohispana de principios del siglo XVIII". Acta Literaria 43: 61-77.

Valdivia, Luis de. 2011 [1604]. "Memorial a Luis de Velasco y el Conde de Monterrey". Escritos inéditos del P. Luis de Valdivia. El alma en la palabra. Ed. José Manuel Díaz Blanco. Santiago de Chile: Universidad Alberto Hurtado; Pontificia Universidad Católica de Chile. 85-99.

.1606. Arte, y gramatica general de la lengva que corre en todo el Reyno de Chile, con vn Vocabulario, y Confellionario. Compueftos por el Padre Luys de Valdivia, de la Compañia de Jefus, en la Prouincia del Piru. Ivntamente con la Doctrina Chrisftiana y Cathecifmo del Concilio de Lima en Efpañol, y dos traducciones del en la lengua de Chile, que examinaron y aprobaron los dos Reverendifsimos feñores de Chile, cada qual la de fu Obifpado. Lima: Francisco del Canto.

Van Dijk, Teun A. 2009. Society and Discourse. How Social Contexts Influence Text and Talk. Cambridge: Cambridge University. . 2012. Discurso y contexto. Un enfoque sociocognitivo. Barcelona: Gedisa. 